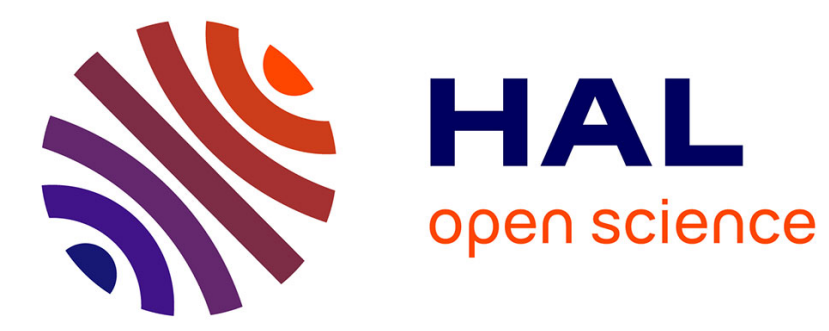

\title{
Optimization of a Phase Change Material Wallboard for Building Use
}

\author{
Frédéric Kuznik, Joseph Virgone, Jean Noel
}

\section{To cite this version:}

Frédéric Kuznik, Joseph Virgone, Jean Noel. Optimization of a Phase Change Material Wallboard for Building Use. Applied Thermal Engineering, 2008, 28 (11-12), pp.1291. 10.1016/j.applthermaleng.2007.10.012 . hal-00498963

\section{HAL Id: hal-00498963 https://hal.science/hal-00498963}

Submitted on 9 Jul 2010

HAL is a multi-disciplinary open access archive for the deposit and dissemination of scientific research documents, whether they are published or not. The documents may come from teaching and research institutions in France or abroad, or from public or private research centers.
L'archive ouverte pluridisciplinaire HAL, est destinée au dépôt et à la diffusion de documents scientifiques de niveau recherche, publiés ou non, émanant des établissements d'enseignement et de recherche français ou étrangers, des laboratoires publics ou privés. 


\section{Accepted Manuscript}

Optimization of a Phase Change Material Wallboard for Building Use

\section{APPLIED}

THERMAL

ENGINEERING

Frédéric Kuznik, Joseph Virgone, Jean Noel

PII:

S1359-4311(07)00350-X

DOI:

10.1016/j.applthermaleng.2007.10.012

Reference:

ATE 2291

To appear in:

Applied Thermal Engineering

Received Date: $\quad 4$ May 2007

Revised Date: 13 August 2007

Accepted Date: $\quad 19$ October 2007

Please cite this article as: F. Kuznik, J. Virgone, J. Noel, Optimization of a Phase Change Material Wallboard for Building Use, Applied Thermal Engineering (2007), doi: 10.1016/j.applthermaleng.2007.10.012

This is a PDF file of an unedited manuscript that has been accepted for publication. As a service to our customers we are providing this early version of the manuscript. The manuscript will undergo copyediting, typesetting, and review of the resulting proof before it is published in its final form. Please note that during the production process errors may be discovered which could affect the content, and all legal disclaimers that apply to the journal pertain. 


\title{
Optimization of a Phase Change Material Wallboard for Building Use
}

\author{
Frédéric Kuznik ${ }^{\mathrm{a}, *}$ Joseph Virgone ${ }^{\mathrm{a}}$ Jean Noel $^{\mathrm{b}}$ \\ a Thermal Sciences Center of Lyon \\ CNRS, UMR 5008, INSA de Lyon, Université Lyon 1 \\ Bât Freyssinet, 40 rue des Arts - 69621 Villeurbanne Cedex, France \\ ${ }^{\mathrm{b}}$ Free-lance scientific software developer \\ 15 place Carnot - 69002 Lyon, France
}

\begin{abstract}
In construction, the use of Phase Change Materials (PCM) allows the storage/release of energy from the solar radiation and/or internal loads. The application of such materials for lightweight construction (e.g., a wood house) makes it possible to improve thermal comfort and reduce energy consumption. A wallboard composed of a new PCM material is investigated in this paper to enhance the thermal behavior of a lightweight internal partition wall. The paper focuses on the optimization of phase change material thickness. The in-house software CODYMUR is used to optimize the PCM wallboard by the means of numerical simulations. The results show that an optimal PCM thickness exists. The optimal PCM thickness value is then calculated for use in construction.
\end{abstract}

Key words: optimization, phase change material, wallboard, energy storage, thermal flow. 


\section{ACCEPTED MANUSCRIPT}

\section{Introduction}

Because we spend most of our time in enclosed spaces, technology to improve the thermal comfort of buildings has steadily increased, causing a corresponding increase in energy consumption. As aIn consequence, this has increased the release of polluting agents into the natural environment. Integrating phase change materials (PCM) into building walls is a potential method for reducing energy consumption in passively designed buildings. This tendency is confirmed by numerous papers. For a review, see in [1].

The use of PCM materials for construction has been a subject of considerable interest in the last decade. An interesting feature is that they can store latent heat energy, as well as sensible energy. As the temperature increases, the material changes phase from a solid to a liquid. As this physical reaction is endothermic, the PCM absorbs heat. Similarly, when the temperature decreases, the material changes phase from a liquid to a solid. As this reaction is exothermic, the PCM releases heat.

The main disadvantage of light weight buildings is their low thermal inertia. Obviously, they tend to undergo large temperature fluctuations due to external cooling or heating loads. Using PCM materials in such buildings allows the reduction of temperature fluctuations. This have been proven in several numerical studies [2], [3], [4], [5]. The main problem lies in how to include PCM in building walls.

A new product, developed by the Dupont de Nemours company is composed

\footnotetext{
* Corresponding author. Tel.: +33-472-438-459; Fax: +33-472-438-522

Email address: frederic.kuznik@insa-lyon.fr (Frédéric Kuznik).
} 


\section{ACCEPTED MANUSCRIPT}

of $60 \%$ of phase change material included in a polymeric structure. The final product looks like a relatively flexible panel. The innovation, in this case, consists in the encapsulation of a significant quantity of active PCM in a thermoplastic polymer which, after transformation into a relatively thin panel, allows for easy installation in any type of building envelope.

In this paper, the optimal value of the PCM wallboard thickness is investigated. First of all, the optimization assumptions are developed concerning optimal wallboard thickness. In order to calculate the optimal value, the inhouse numerical code CODYMUR is used and the results show that an optimal value exists, according to daily external and internal temperature fluctuations.

\section{Optimization assumptions}

This section is devoted to a summary of the assumptions used in this paper during the optimization process. First of all, the physical characteristics of the PCM are developed. The second part deals with the configuration retained for the optimization calculation. The last part presents some heuristic arguments of the optimal research.

\subsection{Phase change material tested}

The new product tested was created by the Dupont de Nemours Society. It is composed of $60 \%$ of micro-encapsulated paraffin, which has a melting temperature of about $22^{\circ} \mathrm{C}$. The final form of the PCM material (figure 1 ) is 


\section{ACCEPTED MANUSCRIPT}

a flexible sheet with a density of $\rho_{P C M}=1019 \mathrm{~kg} / \mathrm{m}^{3}$.

The PCM material heat capacity was measured using a differential scanning calorimeter. The thermal analysis was performed in a range of $0^{\circ} \mathrm{C}-34^{\circ} \mathrm{C}$ with heating rates of $2^{\circ} \mathrm{C} / \mathrm{min}$. The figure 2 shows the measured values of PCM specific heat $c$. This nearly Gaussian distribution corresponds to a narrow phase change [6].

The thermal conductivity of the PCM material was measured using a guarded hot-plate apparatus. The figure 2 shows that under the melting temperature, the thermal conductivity is about $0.22 \mathrm{~W} / \mathrm{mK}$ and decreases, over the melting temperature to about $0.18 \mathrm{~W} / \mathrm{mK}$.

\subsection{Studied configuration}

\subsubsection{General assumptions}

One important hypothesis used during the optimization implementation is that heat transfer is unidirectional in building walls. This assumption is widely used for the thermal simulations of buildings.

The PCM wallboard is used in lightweight buildings (or caravans) to reduce room air temperature fluctuations, in particular when overheating occurs [7]. Then, the wall tested is composed, from the outside, of $2 \mathrm{~cm}$ of wood, a variable insulating material (like glass wool) with a thickness $e_{i n s}$ (for the basic configuration $e_{i n s}=10 \mathrm{~cm}$ ), a variable PCM thickness $e_{P C M}$ and $1 \mathrm{~cm}$ of plaster. A complete description of this test wall is shown in figure 3, and the thermophysical properties of the materials are given in table 1 . The exterior and interior 


\section{ACCEPTED MANUSCRIPT}

heat transfer coefficients are respectively $h_{e}=25 \mathrm{~W} / \mathrm{m}^{2} \mathrm{~K}$ and $h_{i}=7 \mathrm{~W} / \mathrm{m}^{2} \mathrm{~K}$.

The insulation thickness $e_{\text {ins }}$ can vary, but a minimum value is necessary to ensure a correct wall global insulation. In our optimization process, the minimum value of the thickness must fulfill the requirement of the French thermal rules [12] given by the U-value of the wall, $U<0.47 \mathrm{~W} / \mathrm{m}^{2} K$. The U-value is calculated via:

$$
\frac{1}{U}=\frac{1}{h_{e}}+\frac{e_{w p}}{\lambda_{w p}}+\frac{e_{i n s}}{\lambda_{i n s}}+\frac{e_{p}}{\lambda_{p}}+\frac{1}{h_{i}}
$$

Using the given thermophysical properties of table 1, the minimum thickness of insulation is $8 \mathrm{~cm}$ with the wall considered.

\subsubsection{External conditions}

For the building configuration, outdoor boundary conditions and indoor thermal loads are specified while indoor air temperatures may change in time. The main outdoor conditions are external air temperature and solar radiation. These conditions are taken into account using the equivalent temperature $T_{e q}$ calculated using:

$$
T_{e q}=T_{e}+\frac{\alpha S}{h_{e}}
$$

with $T_{e}$ the exterior air temperature, $S$ the total solar radiations, $\alpha$ the solar absorption coefficient of the surface and $h_{e}$ the exterior convective heat transfer.

Figure 4 shows the equivalent temperature calculated for a south vertical wall in Paris in July. From this figure, the assumption of a sinusoidal evolution for exterior equivalent air temperature can be used. Then the optimization process is held using a sinusoidal evolution of the exterior temperature between $15^{\circ} \mathrm{C}$ 


\section{ACCEPTED MANUSCRIPT}

and $35^{\circ} \mathrm{C}$ and within a period of $24 h$. The impact of external conditions is also studied using a sinusoidal evolution of the exterior temperature between $10^{\circ} \mathrm{C}$ and $40^{\circ} \mathrm{C}$.

\subsubsection{Internal conditions}

The interior air temperature is influenced by outdoor conditions, internal loads and, of course, the building composition. Similarly to the assumption used for exterior temperature, a sinusoidal evolution for the interior air temperature is used. For the interior temperature, the selected sinusoidal evolution is taken between $T_{i, \max }$ and $T_{i, \min }$, with a phase difference of $\tau$ with exterior air temperature. As the PCM melting temperature is around $22^{\circ} \mathrm{C}$, only cases with $T_{i, \min }<22^{\circ} \mathrm{C}<T_{i, \max }$ are considered. The boundary conditions are summarized in figure 5 .

\subsection{Heuristic arguments}

The objective of the optimization process is to increase the storage capacity using as little PCM as possible. Two competing trends exist concerning the use of phase change material wallboards in buildings.

When the thickness becomes sufficiently small, the PCM is nearly isothermal. The storage energy process is then only due to temperature changes. In this case, the larger the wallboard, the more important the storage capacity. The storage capacity is then proportional to PCM volume. As the heat transfer is unidirectional, the energy stored by the PCM is proportional to wallboard thickness $e_{P C M}$. In conclusion, in the $e_{P C M} \rightarrow 0$ limit, the total energy stocked 


\section{ACCEPTED MANUSCRIPT}

varies in $\sim e_{P C M}^{1}$. This trend is indicated by the small- $e_{P C M}$ asymptote plotted in figure 6.

The penetration time for transient heat conduction $t_{p}$ can be evaluated by [8]:

$$
t_{p} \sim \frac{(e / 2)^{2}}{\alpha}
$$

where $\alpha$ is the thermal diffusivity of the medium. When $e$ is large, the time needed for the heat to penetrate the PCM becomes larger than $12 h$ : and the storage process cannot be complete during a day. Consider next the limit in which $e_{P C M}$ is large enough to consider a semi-infinite material. Increasing $e_{P C M}$ has no effect on the quantity of stocked energy: in the large- $e_{P C M}$ limit, the total energy stocked varies as $\sim e_{P C M}^{0}$ (constant value). This second asymptote has been added to figure 6 .

The arguments presented below suggest the existence of an optimal thickness, but analytically determining this value is a laborious task. For this reason, numerical simulations are necessary to find the most appropriate value of $e_{P C M}$

\section{Numerical modeling of Phase Change Materials}

The optimization process of the PCM wallboard is performed with the help of numerical simulations. For that purpose, a home made code called CODYMUR is used. This code, developed for thermal simulations of building walls, has been adapted to take into account PCM. The first part of the section is a general presentation of the code, while the second part deals with the needed 
modifications.

\subsection{Presentation of numerical code CODYMUR}

CODYMUR allows for the study of the thermal behavior of a wall, supposing unidirectional heat transfer, under dynamic conditions. It was developed at the Thermal Sciences Center of Lyon in 2002. Considering a wall, external conditions available are climatic data (for various French sites), temperatures, solar radiations,..

CODYMUR carries out calculations for temperatures within a wall as well as thermal flows at the surfaces, as a function of time. The results make it possible to analyze the influence of parameters like the constitution of the wall (thicknesses, materials used for the layers, respective positions of the layers...). The studied wall is made of multiple layers associated with a parameter list characterizing heat exchange (absorption of short wavelength radiation and total surface thermal resistances). The initial conditions are either a temperature solution of the stationary problem at the initial moment, or the temperature of the preceding calculation. The boundary conditions are defined by interior and exterior conditions (which correspond obviously to climatic conditions). An environment has two variables: the air temperature and the solar radiative fluxes.

A demonstration version of CODYMUR (without the PCM) is freely available [13]. 


\section{ACCEPTED MANUSCRIPT}

\subsection{Modifications of CODYMUR}

\subsubsection{General concepts}

The preceding version of CODYMUR [9], [10] supposed that all thermophysical properties of the materials were constant. That made it possible to carry out integration in time by an implicit method. In our case, the density remains constant (equal to $1019 \mathrm{~kg} / \mathrm{m}^{3}$ ). On the other hand, conductivity and specific heat are variable with the temperature of PCM. Also, it was necessary to carry out the following modifications:

- enter conductivity and specific heat varying with temperature,

o modify the integration in time method: use of an explicit method with automatic time step modification.

\subsubsection{Formulation of the thermal problem}

The unidirectional heat transfer problem is given by:

- heat conduction equation

$$
\rho \frac{d H}{d t}=\operatorname{div}(-\vec{q}) \text { with } \vec{q}=-\vec{\nabla} T
$$

- initial conditions

$$
T(x, t=0)=T_{0}(x)
$$

- boundary conditions

$$
\left\{\begin{array}{l}
-\left.\vec{q} \cdot \vec{n}\right|_{e}=-h_{e}\left(T(x=0, t)-T_{e}(t)\right) \\
-\left.\vec{q} \cdot \vec{n}\right|_{i}=-h_{i}\left(T(x=e, t)-T_{i}(t)\right)
\end{array}\right.
$$




\section{ACCEPTED MANUSCRIPT}

with $H$ enthalpy, $\lambda$ the thermal conductivity and $q$ the heat flux.

The enthalpy is linked to the temperature via:

$$
\frac{d H}{d t}=\frac{d H}{d T} \cdot \frac{d T}{d t}
$$

and

$$
C(T)=\frac{d H}{d T}
$$

Then, equation 4 becomes [11], [4]:

$$
\rho C(T) \frac{d T}{d t}=\operatorname{div}(-\vec{q})
$$

A weak formulation of the problem in the calculation domain $\Omega$ which boundary is $\Gamma$ gives:

$$
\begin{aligned}
\int_{\Omega} \rho C(T) \phi_{i} \frac{d T}{d t} & =\int_{\Omega} \phi_{i} \operatorname{div}(-\vec{q}) d \Omega \forall \phi_{i} \text { continuous in } \Omega \\
& =\int_{\Omega}\left[\operatorname{div}\left(-\phi_{i} \vec{q}\right)-\lambda(T) \vec{\nabla} \phi_{i} \vec{\nabla} T\right] d \Omega \\
& =-\left.\int_{\Gamma} \phi_{i} \vec{q} \vec{n}\right|_{\Gamma} d \Gamma-\int_{\Omega} \lambda(T) \vec{\nabla} \phi_{i} \vec{\nabla} T d \Omega
\end{aligned}
$$

With $T(x, t)=\sum T_{j}(t) \phi_{j}(x)$, equation 10 is:

$$
\sum_{j} \frac{d T_{j}}{d t} \cdot \int_{\Omega} \rho C(T) \phi_{i} \phi_{j} d \Omega=-\left.\int_{\Gamma} \phi_{i} \vec{q} \vec{n}\right|_{\Gamma} d \Gamma-\sum_{j} T_{j}\left[\int_{\Omega} \lambda(T) \vec{\nabla} \phi_{i} \vec{\nabla} \phi_{j} d \Omega\right]
$$




\section{ACCEPTED MANUSCRIPT}

If the functions are linear on the interval $\left[x_{i}, x_{i+1}\right]$, the quantity $\vec{\nabla} \phi_{i} \vec{\nabla} \phi_{j}$ is constant and the gradient is also constant. In this interval, $\int_{\Omega} \lambda(T) d \Omega$ is:

$$
\int_{\Omega} \lambda(T) d \Omega=\int_{x_{i}}^{x_{i+1}} \lambda(T) d x=\frac{d x}{d t} \int_{T\left(x_{i}\right)}^{T\left(x_{i+1}\right)} \lambda(T) d T
$$

Integration over time in this system is carried out by an explicit Euler scheme, with an automatic time step calculation: indeed, the characteristic time of this system can become very small and it is necessary to adapt the time step according to the stiffness of the system ([7]). The mass matrix, via the heatstorage capacity, is a function of time: it is thus recomputed at each time step.

\section{Determination of the PCM optimal thickness}

This section is devoted to the determination of optimal PCM thickness. The first part shows the existence of the optimum and its calculation for a specific case. The following parts are concerned with the estimation of the impact of some parameters: insulation thickness, outdoor condition, phase difference and indoor condition. Finally, the optimal value is commented.

4.1 Existence of the optimum: case of $\tau=0 h, T i, \min =18^{\circ} \mathrm{C}, \mathrm{Ti}, \max =$ $25^{\circ} \mathrm{C}$ and $e_{\text {ins }}=10 \mathrm{~cm}$

In order to find the optimal thickness, a set of numerical experiments is held using the modified version of CODYMUR presented in section 3 and for the test case described in section 2. For each thickness $e_{P C M}$, the heat density 


\section{ACCEPTED MANUSCRIPT}

fluxes at the interior and exterior surfaces are computed. Then the stored energy $E_{s}$ per square meter of wall is calculated for a complete day. Obviously, the released energy is equal to the stored one for a repetitive day.

Figure 6 shows that the stored energy is optimal for a PCM thickness of around $1 \mathrm{~cm}$. Layers in which the thickness is higher than this value are less interesting concerning energy storage: for a temperature swing with a period less than $24 h$, only a maximum of $1 \mathrm{~cm}$ of PCM is really affected by heat loads. The value of $e_{P C M}=0 \mathrm{~mm}$ corresponds to the storage capacity of the wall without PCM. The inertia of the light weight wall is double with $1 \mathrm{~cm}$ of phase change material wallboard whereas the total wall thickness and weight only increase respectively by $4 \%$ and $20 \%$.

An interesting phenomenon concerns the presence of a peak figure 6 . When $e_{P C M}>e_{P C M, o p t}$, not all the PCM wallboard is affected by the thermal flow. Nevertheless, the global resistance of the wall increases because of the insulating effect of PCM. Then the thermal flow which passes through the wall decreases, and decreases the storable energy capacity. When $e_{P C M}$ is large enough, the thermal flow cannot pass through the wallboard and then the PCM acts like semi-infinite material: it is a horizontal asymptote.

\subsection{Impact of the insulation thickness}

Figure 7-(a) shows the curves obtained for four insulating material thicknesses:

$e_{i n s}=8 \mathrm{~cm}, e_{i n s}=10 \mathrm{~cm}, e_{i n s}=15 \mathrm{~cm}$ and $e_{i n s}=20 \mathrm{~cm}$, and other parameters corresponding to the reference case of part 4.1. From this figure, the insulation thickness doesn't affect the optimum PCM thickness value. This is due to the 


\section{ACCEPTED MANUSCRIPT}

low exterior heat flux which can pass from the exterior through the insulating material.

\subsection{Impact of outdoor air swing}

The impact of the outdoor air condition is evaluated using two different swings:

a sinusoidal evolution of the exterior temperature between $15^{\circ} \mathrm{C}$ and $35^{\circ} \mathrm{C}$ and the same evolution excepting the minimal and maximal temperatures which are respectively $10^{\circ} \mathrm{C}$ and $40^{\circ} \mathrm{C}$. The other parameters are those of the reference case of part 4.1. The figure 7-(b) shows the results obtained for the optimum value. The external condition doesn't much affect the optimal PCM thickness value. Once again, this is due to the insulating material.

\subsection{Impact of phase difference}

The figure 7-(c) shows the curves obtained for four phase differences $\tau: \tau=$ $-4 h, \tau=-2 h, \tau=0 h, \tau=+2 h$ and $\tau=+4 h$, the other parameters corresponding to the reference case of part 4.1. The optimal value varies between $9 \mathrm{~mm}$ and $11.5 \mathrm{~mm}$.

\subsection{Impact of indoor air swing}

The indoor air temperature swing is a very important parameter of the problem. To evaluate its impact, three cases are tested: the reference case, a few fluctuations case with $T_{i, \min }=20^{\circ} \mathrm{C}$ and $T_{i, \max }=23^{\circ} \mathrm{C}$ and a hard fluctuation case with $T_{i, \min }=8^{\circ} \mathrm{C}$ and $T_{i, \max }=35^{\circ} \mathrm{C}$. The other parameters correspond 


\section{ACCEPTED MANUSCRIPT}

to the reference case.

Figure 7-(d) shows the impact of indoor air swings. The optimum value varies between $9 \mathrm{~mm}$ and $15 \mathrm{~mm}$. However, the higher value correspond to a nonrealistic case because the purpose of the PCM is to reduce significantly the indoor air temperature swing.

\subsection{Conclusions concerning the optimum}

The reference test case shows an optimum of about $10 \mathrm{~mm}$. Even if the optimal thickness value of PCM depends mainly on the indoor air swing, the value of $10 \mathrm{~mm}$ corresponds to a good compromise considering the realty of the swings considered.

In order to illustrate the effect of $10 \mathrm{~mm}$ of PCM compared to other materials, figure 8 summarizes the maximum stockable energy between $18^{\circ} \mathrm{C}$ and $26^{\circ} \mathrm{C}$ for $10 \mathrm{~mm}$ of material and for $24 h$.

\section{Conclusions}

The use of phase change material wallboards allows the enhancement of the thermal inertia of buildings. In order for its use with an optimal storage effect during a complete day, the PCM thickness must be optimized. An optimization process was performed using a test case of a lightweight wall and interior/exterior temperature evolutions within a period of $24 h$.

Numerical simulations were held using a homemade software modified to take into account phase change materials. The results concerning stored energy in 


\section{ACCEPTED MANUSCRIPT}

a complete day function of PCM thickness showed that the optimal thickness is $1 \mathrm{~cm}$. This $1 \mathrm{~cm}$ wallboard allows a doubling of the thermal inertia of the building. This stored energy prevents building rooms from overheating during hot days, and during the night, the released energy increases the minimum air temperature. On the whole, PCM allows a decrease in temperature fluctuations inside rooms.

Given that the software analyzes only the behavior of a single wall, it is not possible to have a direct coupling between this wall and the temperature of the room: it would therefore be necessary to treat the entire room, to take into account solar radiation and air treatment systems. However, the analysis of flows exchanged with a room's interior side of a wall enabled us to quantify the energy stored and released by the wall with a probable assumption of interior temperature changes. This allowed us to calculate the optimal thickness of PCM to be included in room walls.

\section{References}

[1] Tyagi V.V., Buddhi D. PCM Thermal Storage in Buildings: A State of Art. Renewable and Sustainable Energy Reviews; 11: 1146-1166 (2007).

[2] Heim D., Clarke J.A. Numerical modeling and thermal simulation of phase change material with ESP-R, Proceeding of Eight Internationa IBPSA Conference, Eindhoven, August 11-14; 459-466 (2003).

[3] Helmut E.F., Stetiu C. Thermal performance of phase change wallboard for residential cooling application, Report of Energy and Environment Division, University of California, USA; 24p. (1997). 


\section{ACCEPTED MANUSCRIPT}

[4] Manz H., Egolf P.W. Simulation of adiation induced melting and solidification in the bulk of a translucent building façade, Proceeding of Fifth Internationa IBPSA Conference, Madison, August 14-16; 252-258 (1995).

[5] Ibanez M., Lazaro A., Zalba B. Cabeza L.F. An approach to the simulation of PCMs in building applications using TRNSYS. Applied Thermal Engineering; 25: 1796-1807 (2005).

[6] Darkwa K., O'Callaghan P.W. Simulation of phase change drywalls in a passive solar building. Applied Thermal Engineering; 26: 853-858 (2006).

[7] Kuznik F., Virgone J., Roux J.J. Energetic Efficiency of Room Wall Containing PCM Wallboard: A Full-Scale Experimental Investigation. Energy and Buildings; In Press.

[8] Bejan A., Convection Heat Transfer. John Wiley \& Sons, Third Edition, 1994.

[9] Virgone, J. and Noel J. ARCHICUBE et CODYMUR, logiciels de simulation des ponts thermiques et du comportement thermique d'une paroi en régime variable, CIFQ Proceeding, Québec, Canada, 2003.

[10] Virgone, J. and Roux, J.J. and Gao,Y. and Noel, J. J. Développement d'outils d'études dynamiques en thermique du bâtiment, CLIMAMED Proceeding, 20 p., Lisbonne, Portugal, 16-17 april 2004.

[11] Feustel, H. E. and Stetiu, C. Thermal performance of phase change wallboard for residential cooling application, Report LBL-38320, Lawrence Berkeley National Laboratory, 1997.

[12] RT 2005, Arrêté d'application du 24 mai 2006, Journal Officiel de la République Franaise, Texte 14, ,2006.

[13] http://www.jnlog.com/codymur1.htm. 


\section{List of Tables}

1 Thermophysical properties of the materials. 


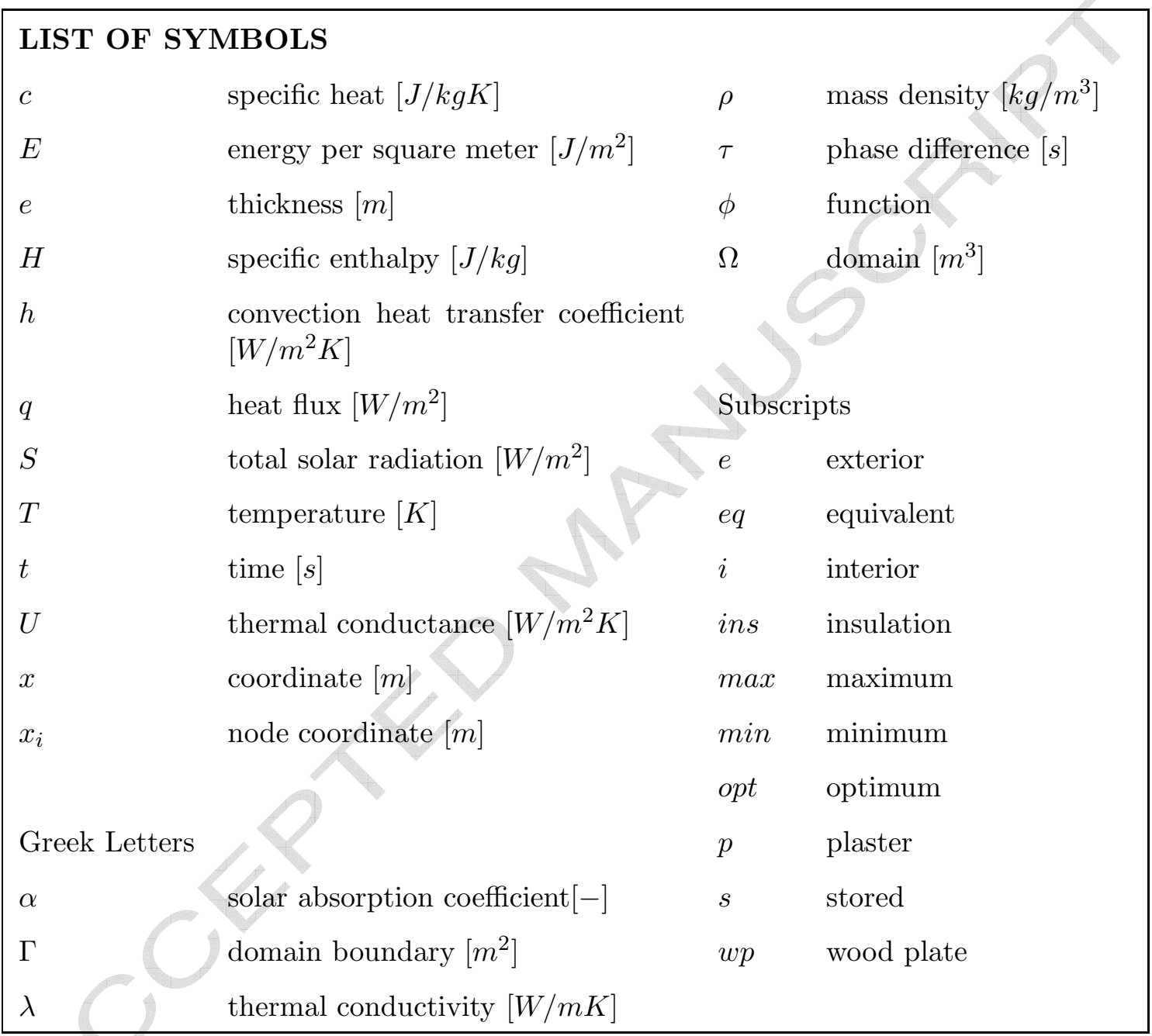


Table 1

\begin{tabular}{lccc}
\cline { 2 - 4 } & $\begin{array}{c}\text { density } \\
{\left[\mathrm{kg} / \mathrm{m}^{3}\right]}\end{array}$ & $\begin{array}{c}\text { specific heat } \\
{[\mathrm{J} / \mathrm{kgK}]}\end{array}$ & $\begin{array}{c}\text { thermal conductivity } \\
{[\mathrm{W} / \mathrm{mK}]}\end{array}$ \\
\hline plaster & 825 & 1000 & 0.25 \\
wood plate & 500 & 1600 & 0.15 \\
insulating material & 15 & 1030 & 0.041 \\
\hline
\end{tabular}

Thermophysical properties of the materials. 


\section{List of Figures}

1 DuPont de Nemours material.

2 Experimental specific heat (left) and thermal conductivity (right) of the PCM material.

$3 \quad$ Test wall composition.

4 Equivalent temperature: vertical wall in Paris - July.

$5 \quad$ Air temperature boundary conditions.

6 Results concerning the stored energy in a complete day $E_{s}$ function of PCM thickness $e_{P C M}$.

7 Impact of various parameters on optimal PCM thickness.

8 Maximum storable energy between $18^{\circ} \mathrm{C}$ and $26^{\circ} \mathrm{C}$ for $10 \mathrm{~mm}$ of material and for $24 h$. 


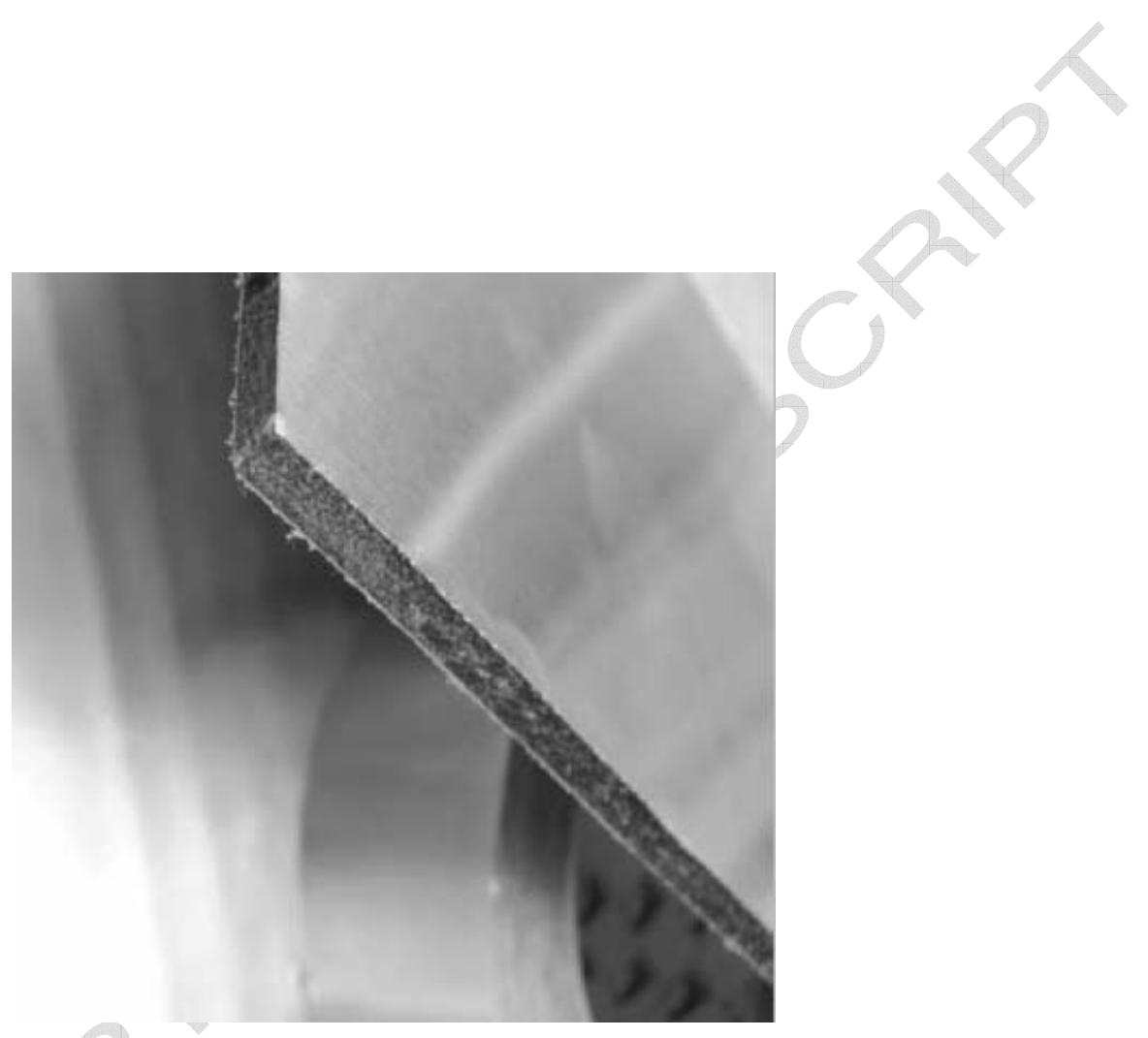

Fig. 1. DuPont de Nemours material. 


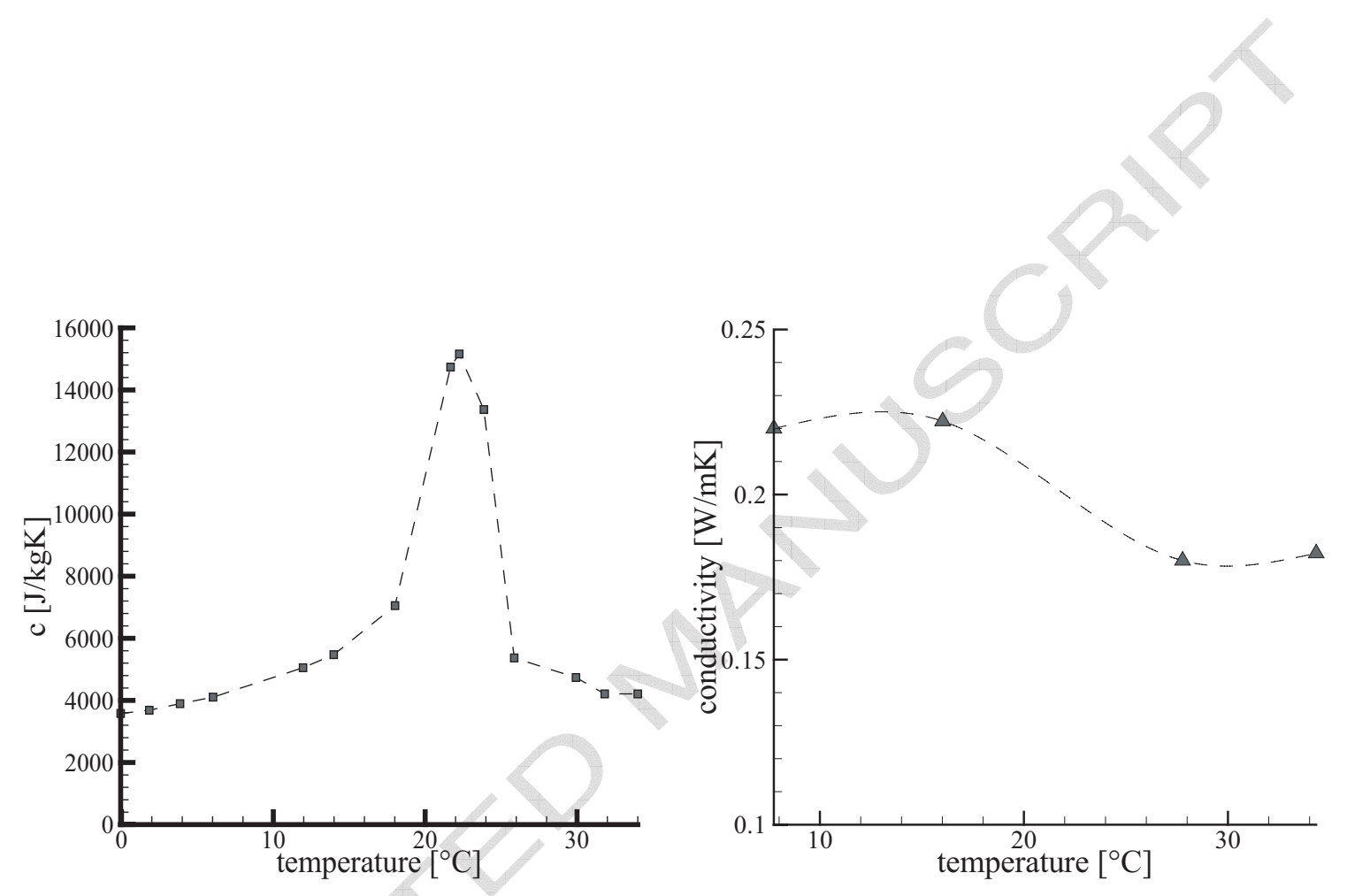

Fig. 2. Experimental specific heat (left) and thermal conductivity (right) of the PCM material. 


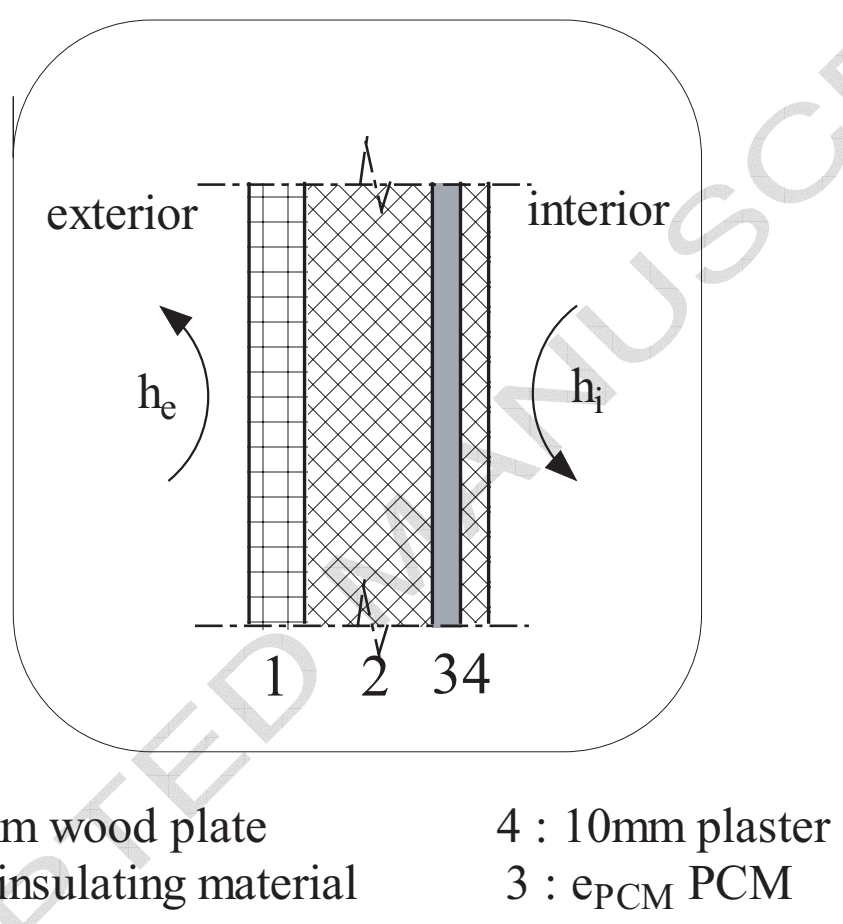

Fig. 3. Test wall composition. 


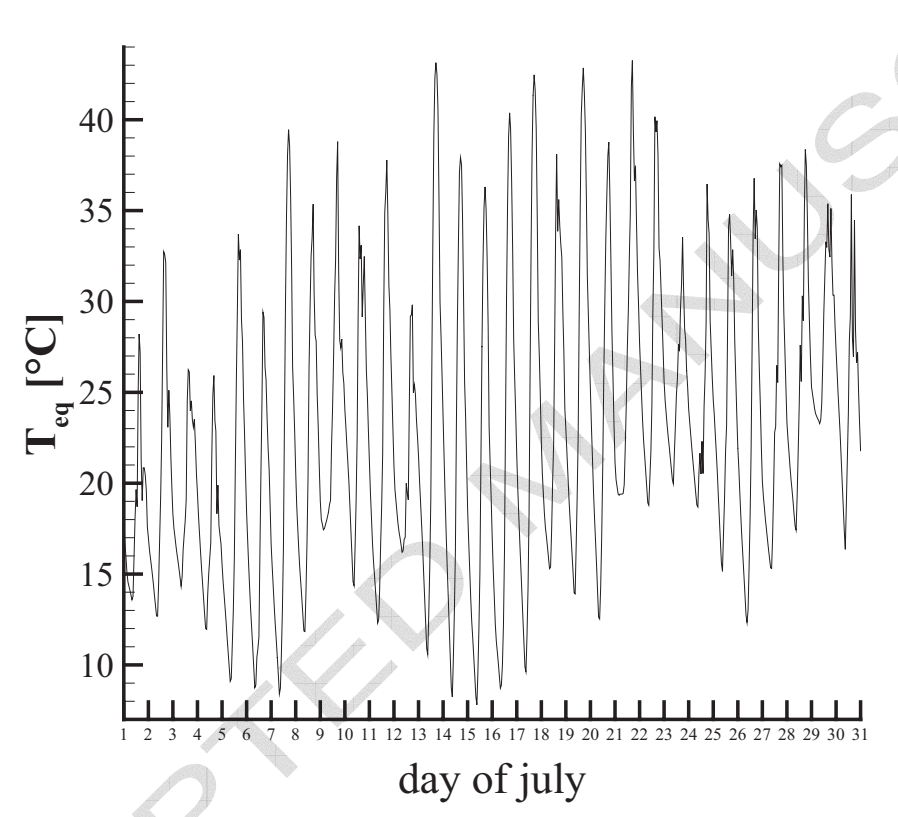

Fig. 4. Equivalent temperature: vertical wall in Paris - July. 


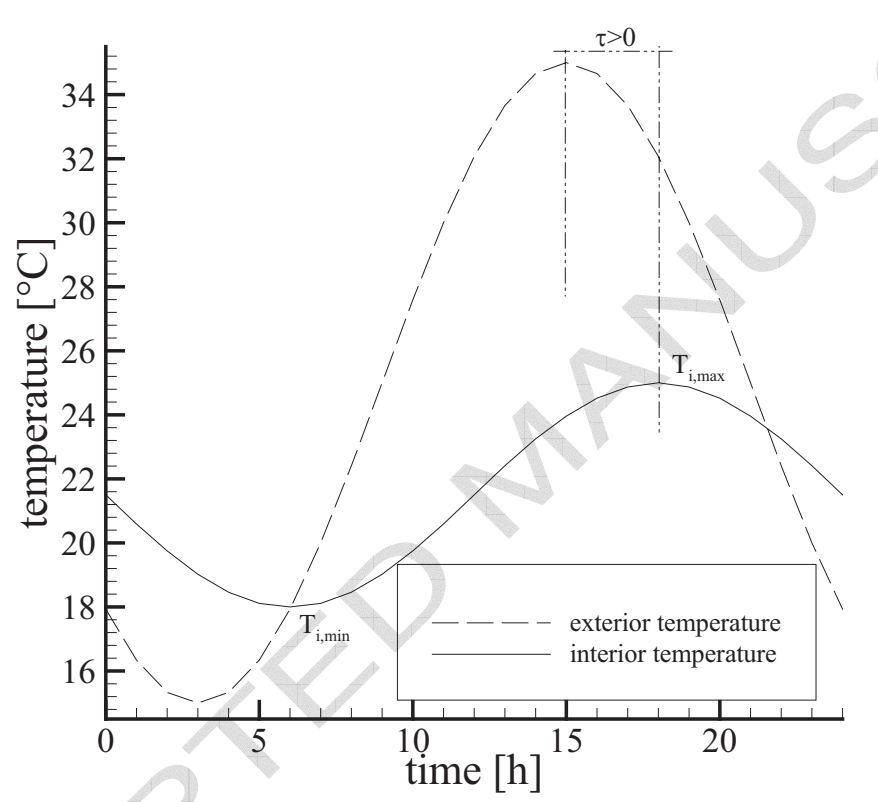

Fig. 5. Air temperature boundary conditions. 


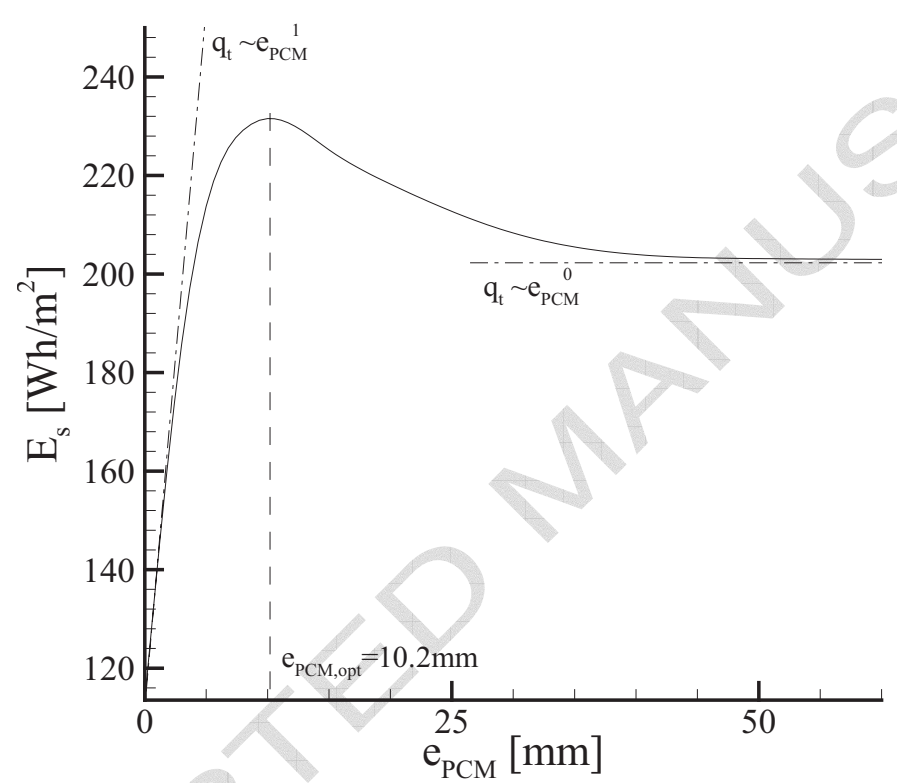

Fig. 6. Results concerning the stored energy in a complete day $E_{s}$ function of PCM thickness $e_{P C M}$. 


\section{ACCEPTED MANUSCRIPT}

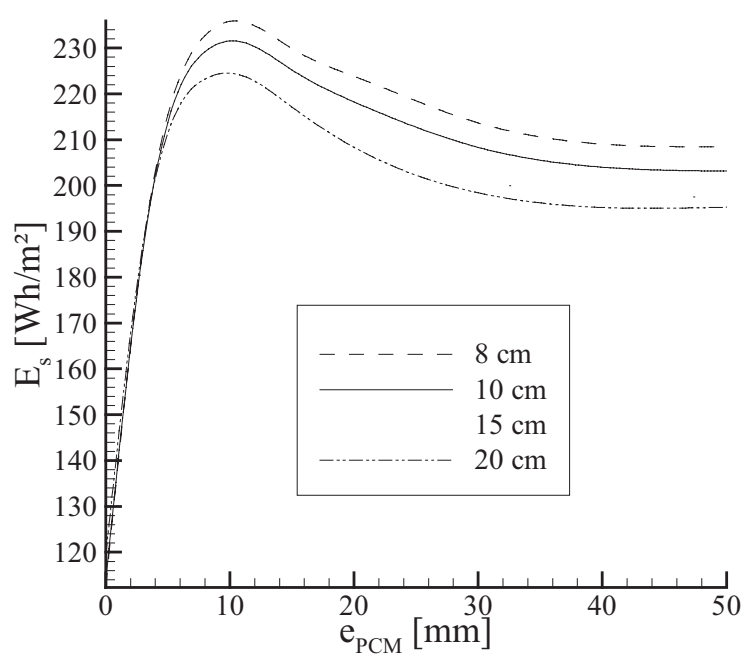

(a) impact of insulation thickness

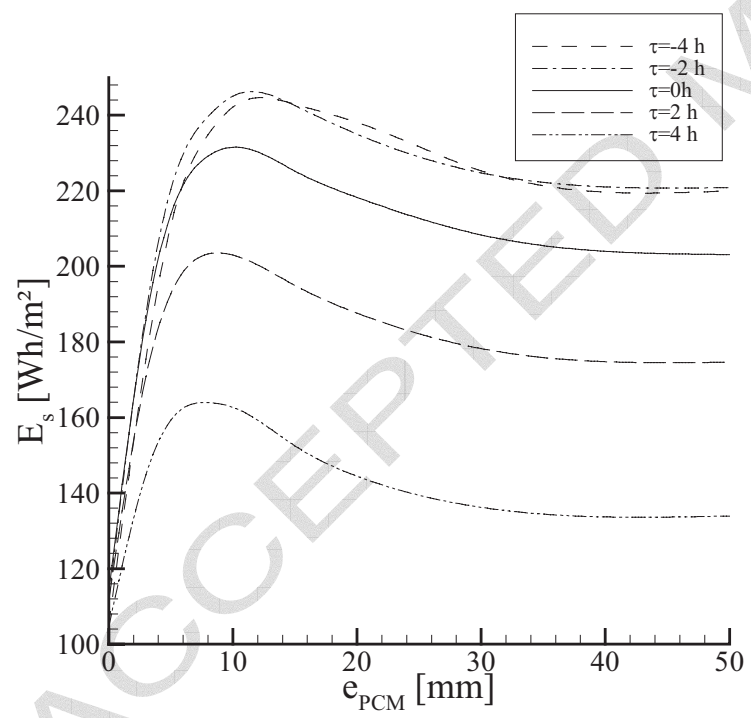

(c) impact of phase difference

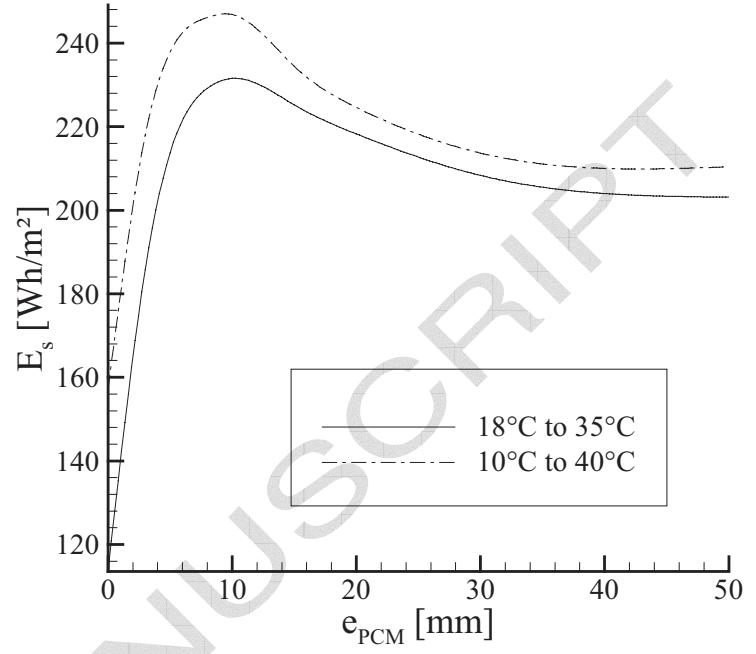

(b) impact of outdoor air swing

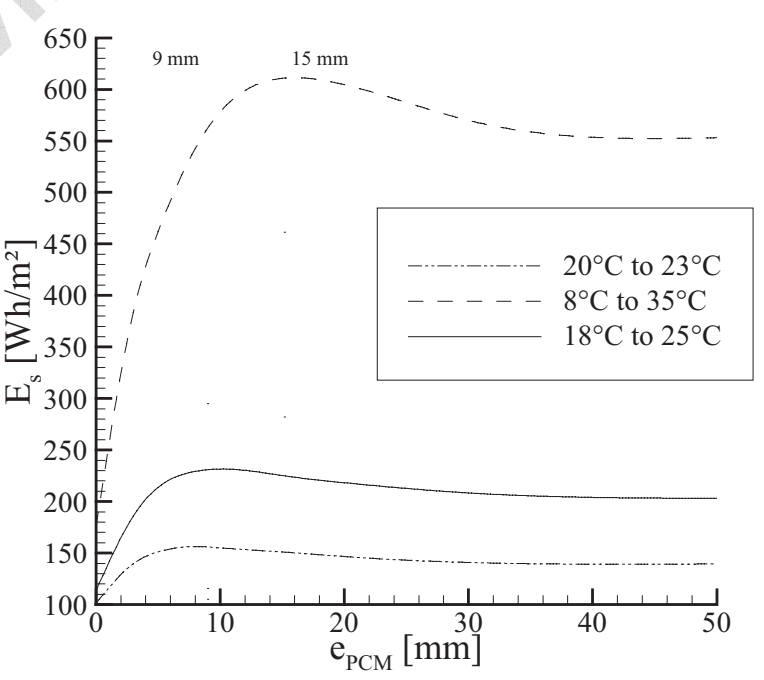

(d) impact of indoor air swing

Fig. 7. Impact of various parameters on optimal PCM thickness. 


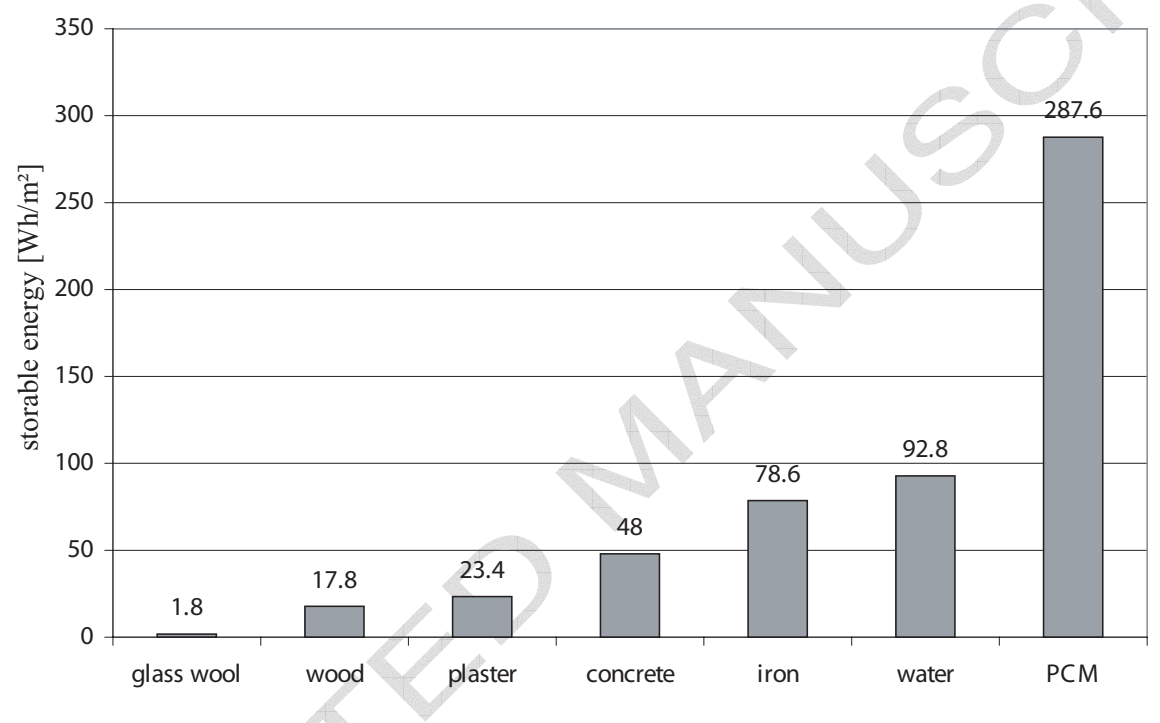

Fig. 8. Maximum storable energy between $18^{\circ} \mathrm{C}$ and $26^{\circ} \mathrm{C}$ for $10 \mathrm{~mm}$ of material and for $24 h$. 